\title{
Differentiation between Clinical and Academic Myocardial Viability. Complementary Myocardial Perfusion SPECT and Low Dose Dobutamine Echocardiography Role vs. Histopathological Study
}

Khaled Elsaban*, Hijji Alsakhri, Ahmed Al-Rashidy and Mohamed Wahdan

Alhada Armed Force Hospital Taif, Saudi Arabia

\begin{abstract}
Background: Rest-Redistribution thallium(R-RD TI) imaging has high negative predictive value (NPV) but low positive predictive value (ppv) for the prediction of recovery of regional myocardial dysfunction after revascularization (Rev). Combining myocardial perfusion (MP) and functional data with nitrate-enhanced gated SPECT MIBI (GSM) at rest appears to be a promising approach for viability detection.
\end{abstract}

Aim of the Study: Differentiate between clinical and academic viability.

Methods: Total of 66 patients with CAD underwent R-RD TI,2 sets of resting GSM using 2 MIBI injections, and echocardiography at rest andafter low dose dobutamine (LDD). One hour before GSM2, trimetazidine (TMZ) andnitrate, had been given. All pts had their echo repeated after (Rev) as a golden standard for clinical viability one year later. Myocardial biopsy was taken for mitochondrial assessment as a golden standard for academic viability.

Results: 389/1122 segments were found to have abnormal resting wall motion (RWM) on echo. 165/217 hypokinetic, 48/102 akinetic and 6/66 dyskinetic showed contractile response for LDD echo. The MP images showed normal uptake, complete, partial reversibility and poor uptake in TI, GSM1 and GSM2 images as following:(58,31,47), $(36,22,35),(198,119,190)$ and $(32,148,50)$ of segments respectively. Sensitivity and specificity of TI, GSM1 and GSM2 and LDD echo for clinical viability had been found respectively to be $(94.9 \%, 74.1 \%),(59.9 \%, 93.6 \%),(93.5 \%$, $90 \%$ ) and $(78.5 \%, 100 \%)$. Mitochondrial degeneration had been found to be more in the segments with partial reversibility and those with poor uptake with sensitivity and specificity of $(90,85.6 \%),(57.2 \%, 94.2 \%),(89.4 \%, 98 \%)$ and $(75 \%, 88.2 \%)$ respectively. From this data we can grade viability into 4 grades.

Conclusion: Clinical definition of viability is better looked for in GSM2. Viability could be assessed into 4 grades.

Keywords: Myocardial viability; Gated SPECT; Trimetazidine; LDD

\section{Introduction}

The potential reversibility of left ventricular dysfunction (LVD) is one of the most important issues to be addressed in patients with an earlier myocardial infarction and severe coronary artery disease. In such cases, myocardial imaging at rest with thallium or Tc- $99 \mathrm{~m}$ labeled agents has been demonstrated to provide clinically relevant data for clinical decision-making [1]. Thallium 201 imaging protocols have gained acceptance for assessment of myocardial viability [24]. Although Tc- $99 \mathrm{~m}$ mibi is widely used for myocardial perfusion imaging, it is not widely used for the assessment of myocardial viability [5-7]. The retention of mibi in myocardial cells is dependent on intact mitochondrial function, which is a surrogate marker of viable myocardium [8]. Unlike Tl-201, Tc-99m mibi does not redistribute significantly in the myocardium after initial uptake, which could potentially be disadvantageous for accurate assessment of viability, especially if the myocardial region is subtended by a critically flowlimiting coronary artery at rest. This may result in significantly lower delivery of the tracer to the myocardium and thus may underestimate viability [9]. To enhance myocardial blood flow, several investigators have used nitrates before tracer administration, and this technique has been shown to improve detection of viable myocardium [10-12]. Furthermore, Bax et al. [13] showed improved accuracy of nitrateenhanced Tl-201 and Tc-99m mibi imaging for the detection of viable myocardium in a meta-analysis. Similar data have also been shown with "biphasic" stress dobutamine echocardiographic response in patients with resting wall motion abnormality $[14,15]$. Nuclear imaging techniques are more sensitive than dobutamine stress echocardiography for detecting viability, but the later is more specific for functional recovery post-revascularization [16-18]. This is probably because nuclear imaging techniques are based on the detection of the integrity of the cell membrane and of preserved perfusion and metabolism (structural viability), whereas dobutamine stress echocardiography relies on the assessment of preserved contractile reserve (functional viability) [18]. Dysfunctional myocardium that has suffered more profound ultrastructural damage will probably lose contractile reserve but can still show intact cell membrane integrity and preserved perfusion and metabolism $[19,20]$. Schinkel et al. [21] added the progressive reduction of contractile reserve in stunned, hibernating, and scarred myocardium supports the hypothesis that stunning, hibernation, and scarring i.e., gradual ultrastructural damage on the myocyte level. Trimetazidine was proved to have a beneficial effect on improvement of mitochondrial integrity in ischemic condition [22].

*Corresponding author: Khaled Elsaban, Alhada Armed Force Hospital Taif, Saudi Arabia, Tel: 201228220993; E-mail: kelsaban@gmail.com

Received September 09, 2017; Accepted September 13, 2017; Published September 20, 2017

Citation: Elsaban K, Alsakhri H, Al-Rashidy A, Wahdan M (2017) Differentiation between Clinical and Academic Myocardial Viability. Complementary Myocardial Perfusion SPECT and Low Dose Dobutamine Echocardiography Role vs. Histopathological Study. J Nucl Med Radiat Ther 8: 340. doi: 10.4172/21559619.1000340

Copyright: (c) 2017 Elsaban K, et al. This is an open-access article distributed under the terms of the Creative Commons Attribution License, which permits unrestricted use, distribution, and reproduction in any medium, provided the original author and source are credited. 
Citation: Elsaban K, Alsakhri H, Al-Rashidy A, Wahdan M (2017) Differentiation between Clinical and Academic Myocardial Viability. Complementary Myocardial Perfusion SPECT and Low Dose Dobutamine Echocardiography Role vs. Histopathological Study. J Nucl Med Radiat Ther 8: 340. doi: $10.4172 / 2155-9619.1000340$

Page 2 of 12

The aim of this study is to assess the interrelation between the different non-invasive techniques (enhanced nuclear imaging and LDD echocardiography) to predict recovery accurately postrevascularization, and correlating these with histopathological mitochondrial changes

\section{Patients and Methods}

\section{Patients selection}

The study population consisted of 66 patients with previous myocardial infarction and left ventricular dysfunction referred for the assessment of coronary artery disease and viability before revascularization in nuclear cardiology unit of $\mathrm{Al}$ Hada Armed Force hospital, Taif and Faculty of Medicine, Taif University in the period of March 2013 till November 2016. The study was approved by the hospital review board, and written informed consent was obtained from all patients. Data from these patients were prospectively collected and analyzed. They were 57 males and 9 females (6.3:1) and the mean age was $54.2+9.1$ years old (Table 1). Patients were eligible for inclusion:

1. If they had severe regional dysfunction in the anatomic distribution of a significantly narrowed or occluded epicardial artery as determined by contrast left ventriculography.

2. If the coronary arteries supplying the area of dysfunction were suitable for coronary artery bypass graft $(\mathrm{CABG})$ or percutaneous coronary intervention (PCI).

All patients had EF below 45\%. Exclusions criteria included:

1. Unstable angina, or myocardial infarction between revascularization and the scintigraphic studies or after intervention.

2. Patients with $3-4+($ moderate to severe) mitral regurgitation or other valvular heart disease.

3. Patients with dilated (non-ischemic) cardiomyopathy.

4. Possible ECG artifacts interfering with gating of gated SPECT (such as absence of stable R-R due to atrial fibrillation, intraventricular conduction block, pacemaker rhythm, etc.).

\section{Methods}

All patients underwent rest-redistribution thallium scintigraphy,

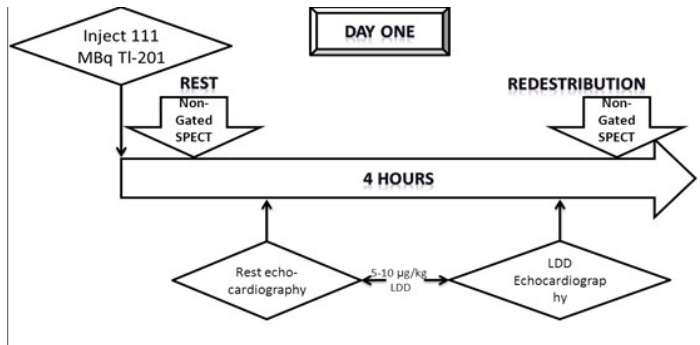

1 (a) and low dose dobutamine echocardiography on day one protocol, then rest gated SPECT MIBI enhanced by TMZ and nitroglycerine on day two protocol, then coronary angiography within the next three months. Subsequently, 22 patients underwent PCI, while 44 patients underwent CABG. The decision concerning the choice of treatment was left to the referring cardiologists and was not based on the results of the viability studies. Figure 1 describes the design protocol as following:

1. Day one: Injection of $111 \mathrm{MBq} \mathrm{Tl}$ then first set of resting $\mathrm{Tl}$ non-SPECT 10 minutes. later. This was followed by resting Echocardiography for assessing both wall motion abnormalities (WMA) and measuring baseline EF (EF1), followed by LDD echocardiography using 5 and $10 \mathrm{ug} / \mathrm{kg} / \mathrm{min}$ according to our previous protocol [23], to assess contractile reserve of the abnormal walls and computing EF and at the end of the first day another set of $\mathrm{Tl}$ redistribution non-gated SPECT was done 3 hours later,

2. Day two: Sublingual nitroglycerine $(10 \mathrm{mg})$ followed 20 minutesutes later by injection of $925 \mathrm{MBq} 99 \mathrm{mTc}-\mathrm{MIBI}$ (Cardiolite kit, Bristol-Myers Squipp Company), then first set of gated SPECT (GSM1) was done one hour post-injection, then after 120 minutes. Three tablets of TMZ (20 mg) were taken as an acute administration followed 90 minutes. later by sublingual nitroglycerine $(10 \mathrm{mg})$ then after 20 minutes. Another dose of 99mTc-MIBI (1295 MBq) was injected followed by second set of gated SPECT 90 minutes. later (GSM2). This would be followed by revascularization (Rev) either by PCI or CABG. Then 6 months later another resting echocardiography was done to reassess WMA in the previous mentioned abnormal walls and measuring post-Rev EF (EF2).

\section{Imaging acquisition of Thallium and MIBI SPECT}

Imaging data were acquired using a double head Siemens E-cam gamma camera fitted with all-purpose low energy collimator, applying a step and shoot method at an angular range of $90^{\circ}$, the angular step is $6^{\circ}$, the frame time is $40 \mathrm{~s}$, the matrix is $64 \times 64$ for both tracers. For the gated rest, the angular range is $90^{\circ}$, the angular step is $6^{\circ}$, the frame per cycle is 8 , the frame time is $40 \mathrm{~s}$, the matrix is $64 \times 64$, the zoom is 1.28 and the ECG was connected. The methods have been described in detail in previous publications [24].

Image analysis: Comprehensive semiquantitative perfusion defect analysis using 17-segment visual analysis has been used to match echocardiographic findings [25]. The 17-segment scoring system is

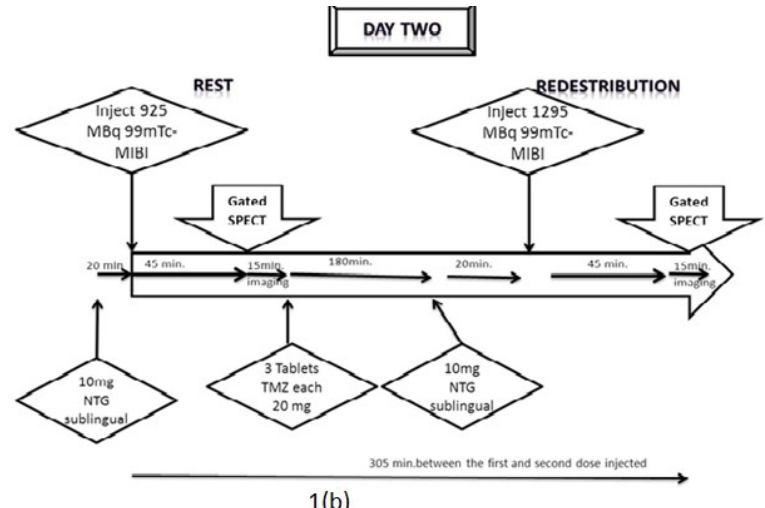

1 (b)

Figure 1: Protocol of myocardial perfusion imaging and echocardiogram at rest and during LDD. (a): Revealed R-RD thalliumprotocol. During the 3 hour interval resting-LDD echocardiogram was done (b): Revealed resting gated MIBI SPECT imaging without and after TMZ and nitrate administration. On cardiac catheterization endomyocardial biopsy was taken for electronmicroscopic assessment of mitochondria. Then patient had been subjected to revascularization followed by resting echocardiography 6 months later. (LDD=low dose dobutamine, R-RD=rest-redistribution, TMZ=trimetazidine). 
Citation: Elsaban K, Alsakhri H, Al-Rashidy A, Wahdan M (2017) Differentiation between Clinical and Academic Myocardial Viability. Complementary Myocardial Perfusion SPECT and Low Dose Dobutamine Echocardiography Role vs. Histopathological Study. J Nucl Med Radiat Ther 8: 340. doi: $10.4172 / 2155-9619.1000340$

Page 3 of 12

based on three-short axis slices (distal, mid, and basal) to represent the entire left ventricle, with the apex represented by one segment visualized in a mid-vertical long axis image. Each of the 17 segments has a distinct name (number) and visual score (Figure 2). Then the summed rest score (SRS1) and (SRS2) were defined as the summed rest scores of the rest or redistribution scores for $\mathrm{Tl}$ and of the GSM1 and GSM2 for MIBI. The summed difference score (SDS), measuring the degree of reversibility, was defined as the difference between the SRS1 and the SRS2. In addition, wall motion and thickening analysis were assessed according to echocardiography assessment (below). Viability was defined as $\geq 20 \%$ improvement in perfusion or function (thickening rather than wall motion) [26,27].

\section{Echocardiography}

Echocardiographic studies were performed under resting condition. Standard tomographic views of the left ventricle were obtained from the parasternal long-axis and short-axis views and from the apical 4- and 2-chamber views, with particular attention paid to the optimization of regional function. All studies were performed on a Hewlett-Packard Sonos 1000 ultrasound system equipped with a $2.5-\mathrm{MHz}$ transducer and were recorded on half-inch VHS tape. Echocardiograms were analyzed by 2 independent readers who were unaware of the clinical and angiographic data. Discrepancies were resolved by means of consensus. For the analysis of wall motion, the left ventricle was divided into 17 segments corresponding to the scintigraphic regions (Figure 2).

For each segment, wall motion was scored according to the recommendations of the American Society of Echocardiography [28], on a scale of 1 to 3 , in which 1 indicated normal, 2 indicated hypokinesia (reduced wall thickening and inward motion), and 3 indicated akinesia (absence of wall motion and of systolic thickening) or dyskinesia (paradoxical outward motion in systole). To assess the recovery of function, resting, LDD echo and follow-up echocardiograms were compared in all patients. For each segment, recovery of function (viability) was defined as an improvement of 1 or more point after Rev.28

\section{Coronary angiography}

Coronary angiography was performed by means of Judkin's technique. It was reported by 2 independent, experienced observers. Stenoses of coronary vessels were coded according to American Heart Association criteria [29]. The presence of significant (50\% coronary diameter reduction) stenosis in the proximal coronary arteries or their major branches was assessed using caliber measurement.

\section{Myocardial biopsy}

During coronary angiography, Stanford Caves-Shulz bioptome was introduced through the femoral artery (using a performed sheath) into the left ventricle under umbrella of aspirin and heparin. Six endomyocardial biopsies were performed safely under fluoroscopic guidance and taken according to American guidance 2007, (mainly from the septum and lateral wall, and suspected infarct area supplied by the occluded artery but avoiding the thinner wall) and sent for electron microscopical examination looking for mitochondrial changes as following; Mitochondrial Area Measurements were generated from transmission electron microscopy images with a magnification of 20000X; images were taken from at least two sections of a minutesimum of 10 sections apart within the tissue block and were positioned to avoid blood vessels. Image software was used to calculate the area by drawing around of each individual mitochondrion analysed [30].

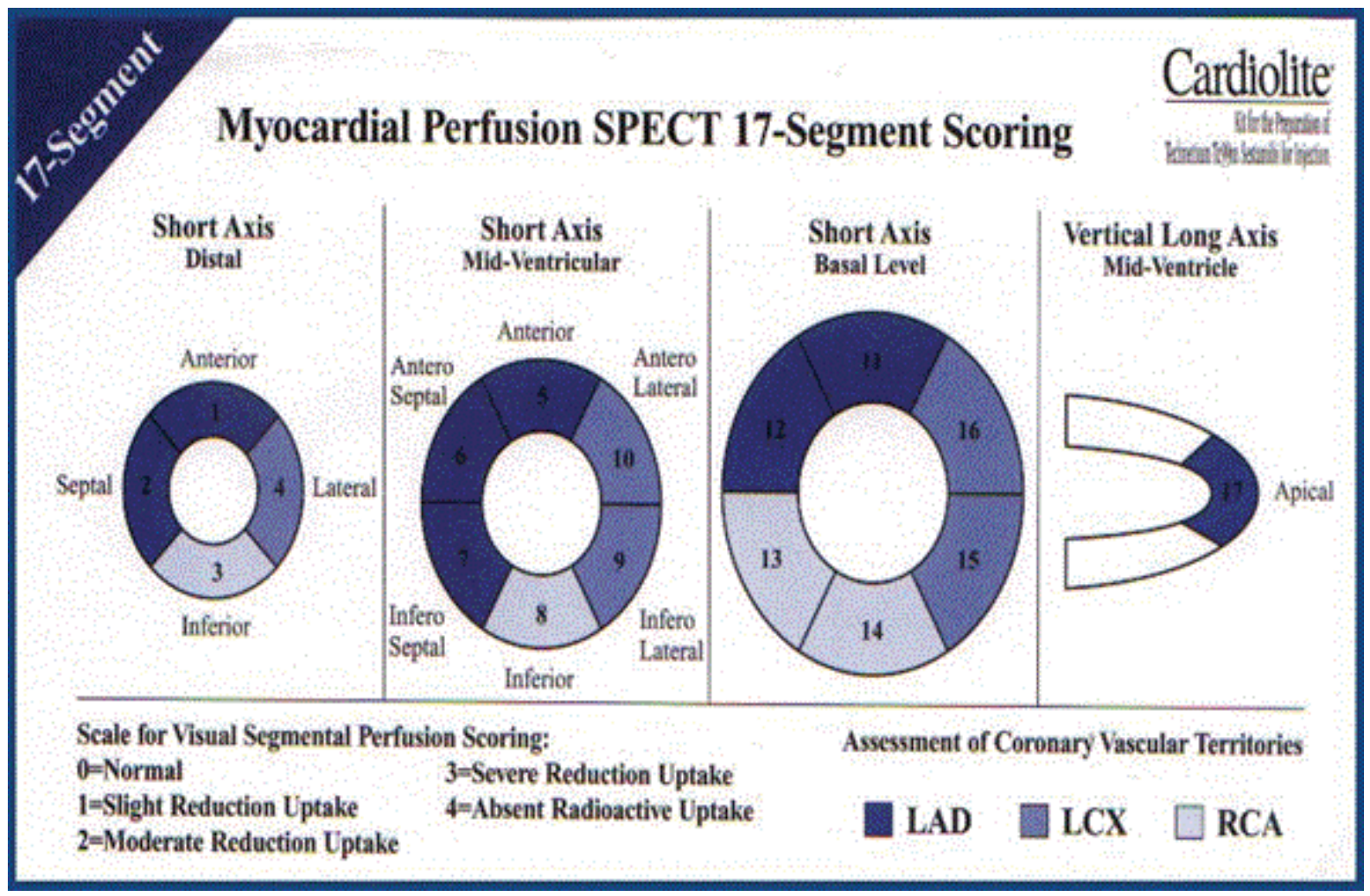

Figure 2: 17 Myocardial Segments for SPECT and echocardiography interpretation and matching. 
Citation: Elsaban K, Alsakhri H, Al-Rashidy A, Wahdan M (2017) Differentiation between Clinical and Academic Myocardial Viability. Complementary Myocardial Perfusion SPECT and Low Dose Dobutamine Echocardiography Role vs. Histopathological Study. J Nucl Med Radiat Ther 8 : 340. doi: $10.4172 / 2155-9619.1000340$

Page 4 of 12

Mitochondrial Density Measurements were generated from at least two images at magnification of $3000 \mathrm{X}$ taken from 2 sections at least 10 sections apart within the tissue block from each patient. Every mitochondria visible by eye was marked with a dot within a counting frame of $286 \mu \mathrm{m}^{2}$ positioned to avoid blood vessels.

Quantification of ultrastructural defects quantification of mitochondrial ultrastructural defects was performed from identical images used for the area measurements as indicated above. Every mitochondria of myocardial origin was analyzed and based on its ultrastructural appearance classified into one of following categories [30]: Type I-normal appearing mitochondria with mostly longitudinally oriented and tightly packed cristae; Type II - abnormal mitochondria with either swollen, irregular, or whorling cristae in which the characteristic longitudinal orientation and/or the tight and regular spacing of cristae were lost or severely compromised. Type III which showed increasing numbers of mitochondria with a discontinuous outer membrane or deficient cristae, in which the cristae order was distorted by holes with an empty matrix. Finally, Type IV where some mitochondria with swollen and deficient cristae, or swollen cristae and discontinuous outer membrane were present. At least 75 mitochondria were analyzed for each patient. Raw data per individual patient have been expressed as percentage of total number of mitochondria analyzed.

No complications were recorded during or after endomyocardial biopsy.

\section{Statistical analysis}

The current study aimed to differentiate between clinical and academic definition of myocardial viability testing. Clinical viability test can identify patients with ischaemic heart disease and left ventricular dysfunction who can potentially benefit from improved cardiac function after revascularization together with long-term survival [31]. While academic viability can detect integrity of myocardial cell structure inspite of ischemia. Data were expressed as the mean plus or minutesus $1 \mathrm{SD}$. Differences between mean values were assessed by means of the Student unpaired t test, with Bonferroni's correction when appropriate. Sensitivity, specificity, and diagnostic accuracy were based on their standard definitions. Frequency data were compared by means of the McNemar or Chi-square test. A P value less than 0.05 was considered to be statistically significant. The statistic was used as a measure of agreement between visual and quantitative mibi analysis. A value of 1 denotes perfect agreement, and 0 indicates no agreement beyond chance. In general, values of 0.6 or greater are considered to be indicative of good agreement [32].

\section{Results}

\section{Demographic data}

The current study included 57 males and 9 females (6.3:1). Their mean age was $54.2+9.1$ years (Table 1). The commonest presenting symptom was chest pain $(72.7 \%)$, and the most common risk factors were smoking (57.6\%) and hypertension (48.5\%). Fifty six cases $(84.8 \%)$ showed Q wave in the resting ECG.

\section{Resting echocardiogram}

Figure 3 reveals that out of the 1122 myocardial segments, 733 segments were found to be normal while the 389 showed abnormal wall motion. These were distributed as 217 hypokinetic, 104 akinetic and 67 dyskinetic.

\begin{tabular}{|c|c|c|}
\hline Parameters & Number & Percentage \\
\hline \multicolumn{3}{|l|}{ Sex and age } \\
\hline \multicolumn{3}{|l|}{ Sex } \\
\hline Males/female ( $\mathrm{N}$ and \%) & $57 / 9$ & $86.4 / 13.6$ \\
\hline Male: Female ratio & $6.3: 1$ & \\
\hline Age (Mean \pm SD) & \multicolumn{2}{|c|}{$53.67 \pm 12.1$} \\
\hline \multicolumn{3}{|l|}{ Risk factors } \\
\hline Smoking & 38 & 57.6 \\
\hline HTN & 32 & 48.5 \\
\hline $\mathrm{DM}$ & 24 & 36.4 \\
\hline Hyperlipidemic & 24 & 36.4 \\
\hline $\mathrm{FH}$ & 20 & 30.3 \\
\hline \multicolumn{3}{|l|}{ Clinical presentation } \\
\hline Chest pain & 48 & 72.7 \\
\hline Dypsnea & 35 & 53 \\
\hline Palpitation & 21 & 31.8 \\
\hline LL edema & 12 & 18.2 \\
\hline Q wave in resting ECG & 56 & 84.8 \\
\hline \multicolumn{3}{|l|}{ Coronary angiography } \\
\hline Left main & 3 & 4.5 \\
\hline LAD & 58 & 87.9 \\
\hline $\mathrm{D} 1$ & 31 & 47 \\
\hline $\mathrm{D} 2$ & 6 & 9.1 \\
\hline $\mathrm{LCX}$ & 44 & 66.7 \\
\hline OM1 & 33 & 50 \\
\hline OM2 & 8 & 12.1 \\
\hline RCA & 48 & 72.7 \\
\hline \multicolumn{3}{|l|}{ No. of vessels affected } \\
\hline $1 \mathrm{VD}$ & 14 & 21.2 \\
\hline 2 VD & 14 & 21.2 \\
\hline $3 \mathrm{VD}$ & 38 & 57.6 \\
\hline \multicolumn{3}{|c|}{ Mitochondrial ultrastructure* } \\
\hline \multicolumn{3}{|c|}{ Type I } \\
\hline Type II & 233 & 60 \\
\hline Type III & 59 & 15 \\
\hline \multirow[t]{2}{*}{ Type IV } & 66 & 17 \\
\hline & 31 & 8 \\
\hline
\end{tabular}

Table 1: Demographic data of the studied patients.

\section{Coronary angiography}

Table 1 reveals that half of the cases showed three vessel disease (38/66), while 14 showed one vessel disease and 14 showed two vessel disease. Three cases showed left main involvement while left anterior descending (LAD) was involved in 58 cases.

\section{Non-invasive assessment of viability}

Clinical viability was defined in the current study by the normalization of segments with abnormal wall motion in the rest echocardiography done 6 months post-revascularization, which was considered accordingly the golden standard for clinical viability with true positive 279 and true negative 110 .

Low Dose Dobutamine Echocardiography and Pre-revascularization Contractile Reserve: Figure 3 reveals contractile reserve with LDD in $165 / 217(76 \%)$ of hypokinetic, 48/102 (47.1\%) of akinetic, and 6/66 (9.1\%) of dyskinetic myocardial segments. On the other hand, postrevascularization normal myocardial segments increased from 733 to 910 with unexpected improvement in 12 hypokinetic segments in addition to the predictable 165 segments. Hypokinetic segments 
Citation: Elsaban K, Alsakhri H, Al-Rashidy A, Wahdan M (2017) Differentiation between Clinical and Academic Myocardial Viability. Complementary Myocardial Perfusion SPECT and Low Dose Dobutamine Echocardiography Role vs. Histopathological Study. J Nucl Med Radiat Ther 8 : 340. doi: $10.4172 / 2155-9619.1000340$

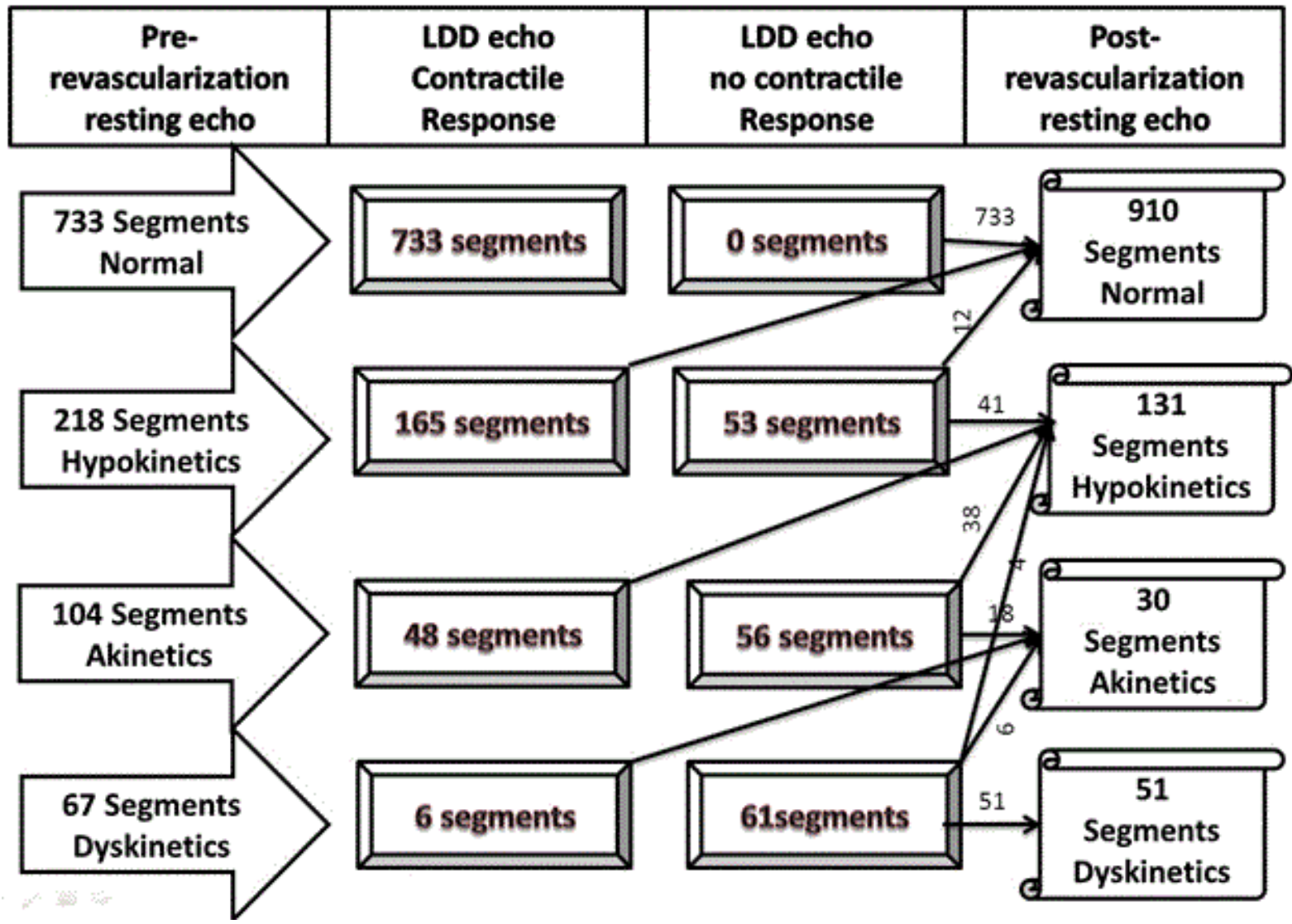

Figure 3: Distribution of myocardial segments according to wall motion status at pre-revascularization resting and LDD echocardiography and postvascularization resting echocardiography. Note the improvement in some of hypokinetic, akinetic and dyskinetic segments postrevascularization. These segments were predicted to be more on LDD.

decreased from 217 to 131 segments with unexpected improvement of 38 akinetic and 4 dyskinetic segments to be hypokinetic segments (from moderate to severe degree). Akinetic segments decreased from 104 to 30 segments with unexpected improvement in 6 dyskinetic segments in addition to improvement of 6 other dyskinetic segments. Finally, the dyskinetic segments became only 51 segments. This means that post-revascularization resting echocardiography showed viability in 60 segments that were considered non-viable pre-revascularization by LDD echocardiography. This leads to sensitivity of $78.5 \%$, and since all segments with pre-revascularization contractile reserve were improved, the specificity was $100 \%$ (Figure 4 ). Thus, the positive predictive value (PPV) and negative predictive value (NPV) for LDD echocardiography were found to be $100 \%$ and $64.7 \%$ respectively (Figure 4 ). Degree of matching between LDD and post resting echo was found to be $84.6 \%$ and $\mathrm{P}<0.001$ (Table 2).

\section{Myocardial perfusion and clinical viability assessment}

Rest-Redistribution Tl: Figure 5 shows that out of the abnormal 389 segments (in resting echo), 58 shows normal uptake and 97 with severe reduction of uptake till the end of the study. The rest (234) shows mild to moderate reduction of uptake in the first setting of images, while in the second image 36 segments were normalized and 198 showed partial reversibility. Accordingly, 288 myocardial segments were diagnosed as viable myocardium by Tl. Following revascularization, 263 segments showed normal wall motion while the rest showed still wall motion abnormality, with sensitivity $94.9 \%$, specificity $74.1 \%$, PPV $90.1 \%$ and NPV 85.6\% (Figure 4a) [29]. Degree of matching between $\mathrm{Tl}$ and postrevascularization resting echo was high; $88.9 \%$ and $\mathrm{P}<0.01$ Table 2 .

Nitrate enhanced 99mTc-MIBI gated SPECT:

1. Without TMZ: Out of the abnormal 389 segments, 31 segments showed normal MIBI uptake, 143 showed mild to moderate reduction of uptake and 215 severe reduction of uptake (Figure 6). Accordingly, 174 were diagnosed as viable with sensitivity of $59.9 \%$ and specificity of $93.6 \%$, PPV $96 \%$ and NPV $47.9 \%$. The degree of matching between GSM1 and post-revascularization resting echo was modest 69.4\% and $\mathrm{P}<0.05$.

2. With TMZ: Adding TMZ increased segments with normal uptake to 47 segments, mild to moderate reduced uptake to 225 segments while segments with severe reduction of uptake decreased in number to 117 (Figure 6). Accordingly, ability of GSM2 to detect clinical viability increased to 272 segments with sensitivity of $93.5 \%$, specificity of $90 \%$, PPV $95.8 \%$, NPV $84.6 \%$. The degree of matching between GSM2 and post-revascularization resting echo increased to be the strongest $92.5 \%$ and $\mathrm{P}<0.0001$.

3. Academic Viability: Some myocardial segments with abnormal wall motion in the pre-revascularization echocardiography with or without LDD were still viable but showed delayed recovery (more than 1 year). The current study assessed their existence by 


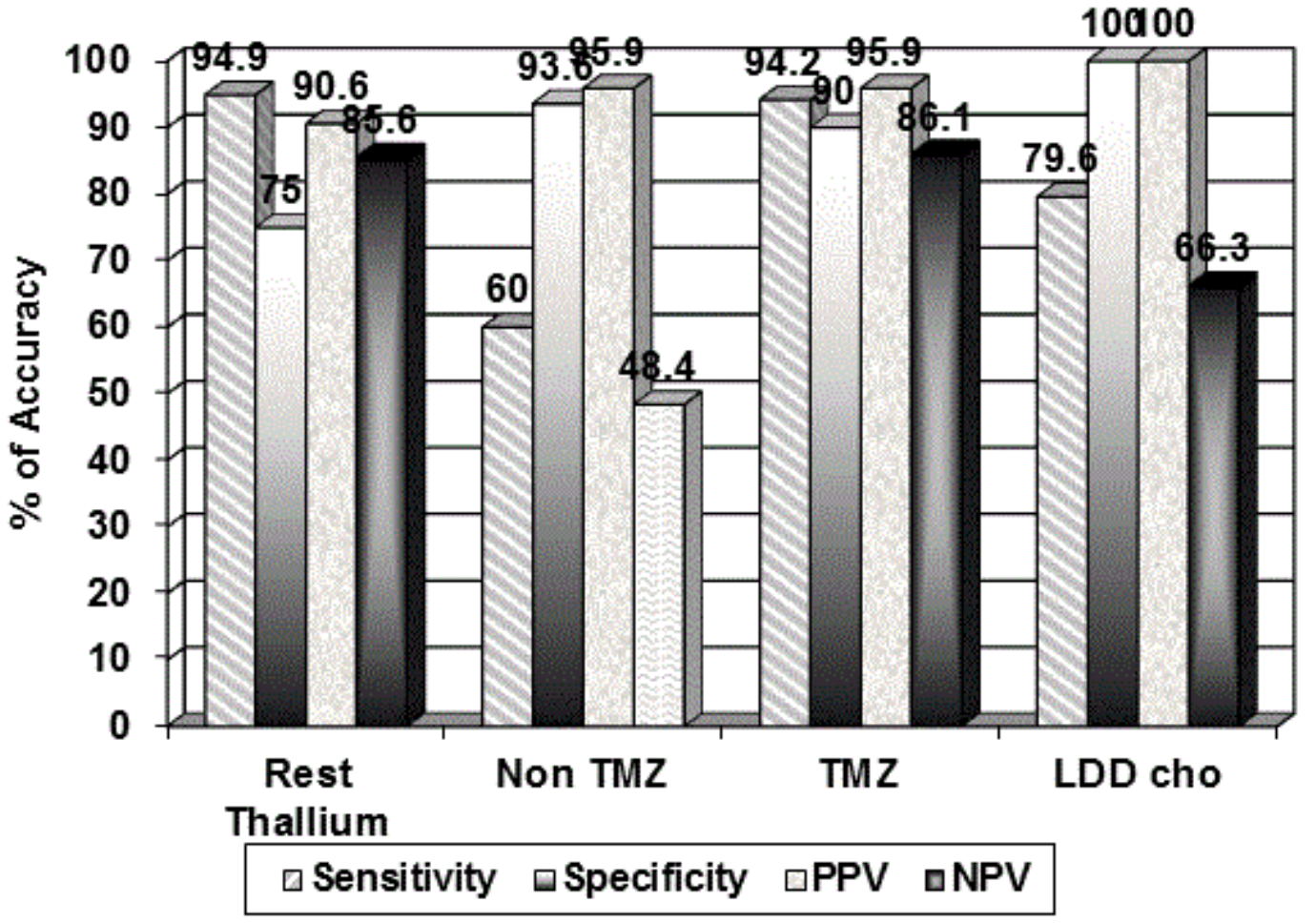

Figure 4: Sensitivity, specificity, positive predictive value (PPV) and negative predictive value (NPV) of Resting Thallium, Gated SPECT MIBI with and without TMZ and LDD Echo to predict recovery of Function post-revascularization. Note the highest sensitivity was R-RD thallium, highest specificity was non-TMZ MIBI and LDD ECHO, but TMZ MIBI images could achieve both the highest sensitivity of thallium and specificity of non-TMZ MIBI and LDD ECHO.

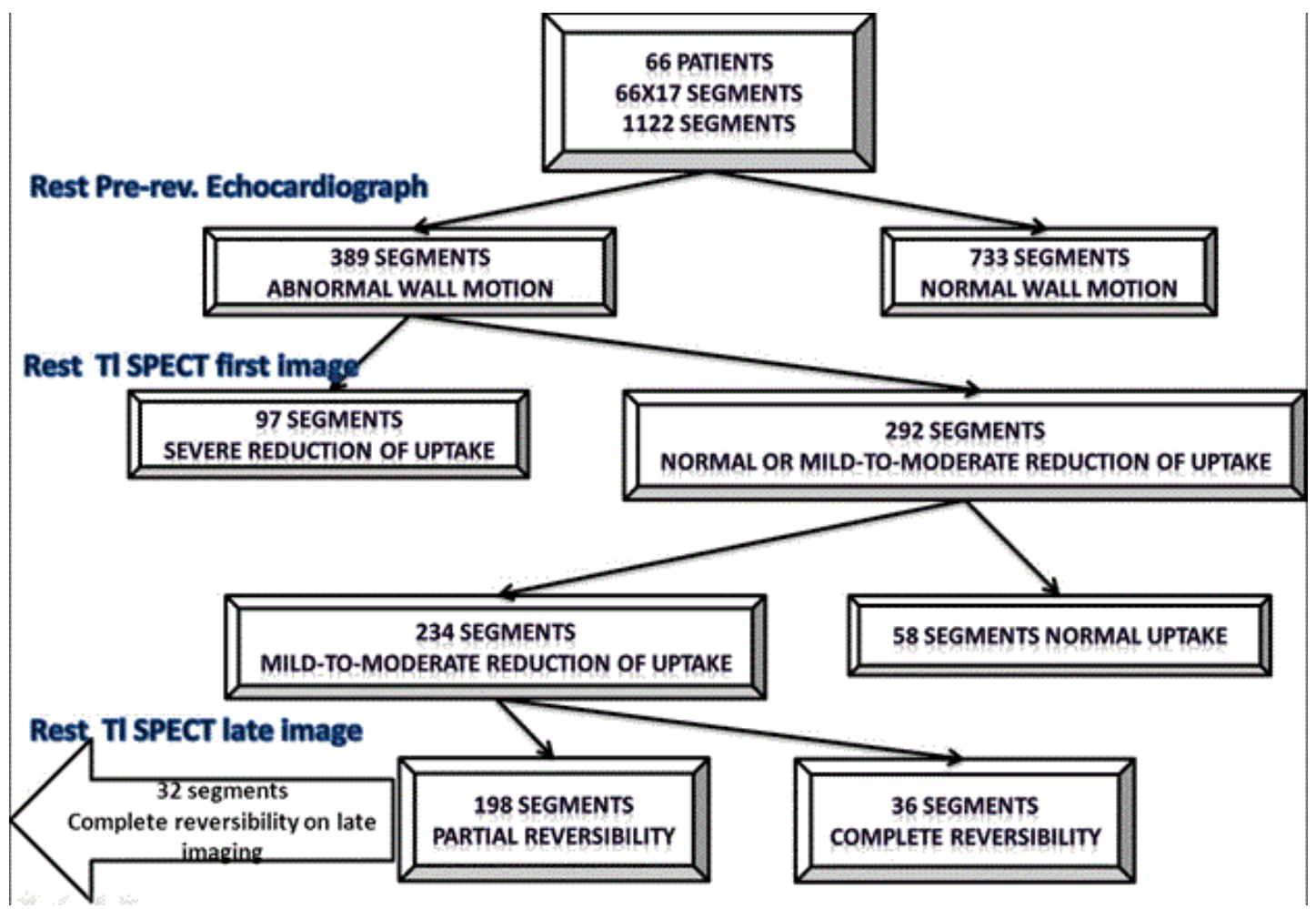

Figure 5: Viability as assessed by Thallium uptake. Sequential inter-relationship findings between resting echocardiogram pre and post revascularization and R-RD thallium findings. Note that most of segments with mild-to-moderate reduction of thallium uptake showed partial reversibility after revascularization. 
Citation: Elsaban K, Alsakhri H, Al-Rashidy A, Wahdan M (2017) Differentiation between Clinical and Academic Myocardial Viability. Complementary Myocardial Perfusion SPECT and Low Dose Dobutamine Echocardiography Role vs. Histopathological Study. J Nucl Med Radiat Ther 8: 340. doi: $10.4172 / 2155-9619.1000340$

Page 7 of 12

\begin{tabular}{|c|c|c|c|}
\hline & \multicolumn{2}{|c|}{ Pre-vascularization } & Total \\
\hline & Viable & \multicolumn{2}{|c|}{ Non-Viable } \\
\hline & 263 & 14 & 277 \\
\hline & 29 & 83 & 112 \\
\hline & 292 & 97 & 389 \\
\hline \multicolumn{4}{|c|}{ Degree of matching=346/389=88.9\%, P<0.01 } \\
\hline \multicolumn{4}{|c|}{ Non-TMZ gated SPECT } \\
\hline Viable & 167 & 112 & 279 \\
\hline \multirow[t]{2}{*}{ Non-Viable } & 7 & 103 & 110 \\
\hline & 174 & 215 & 389 \\
\hline \multicolumn{4}{|c|}{ Degree of matching=270/389=69.4\%, $P<0.05$} \\
\hline \multicolumn{4}{|c|}{ TMZ gated SPECT } \\
\hline Viable & 261 & 18 & 279 \\
\hline \multirow[t]{2}{*}{ Non-Viable } & 11 & 99 & 110 \\
\hline & 272 & 117 & 389 \\
\hline \multicolumn{4}{|c|}{ Degree of matching $=360 / 389=92.5 \%, P<0.0001$} \\
\hline \multicolumn{4}{|c|}{ LDD echocardiography } \\
\hline Viable & 219 & 60 & 279 \\
\hline \multirow[t]{2}{*}{ Non-Viable } & 0 & 110 & 110 \\
\hline & 219 & 166 & 389 \\
\hline
\end{tabular}

Table 2: Degree of matching between pre-revascularization Thallium SPECT (rest-redistribution), LDD echocardiography, gated MIBI SPECT with and without trimetazidine (TMZ) and post-revascularization resting echocardiography.

the mitochondrial status studied by the electron microscope which was considered as the golden standard in this issue. Accordingly, mitochondrial state type I and II were considered viable and predict recovery (true positive [TP] were 292 segments showing normal and abnormal wall motion in the whole studied echocardiography), while Type III and IV were considered true negative [TN] for viability (97 segments).

Mitochondrial changes and radionuclides uptake vs. contractility

Table 3 revealed the distribution of mitochondrial changes with ischemia, 4 types had been detected and distributed in all segments with variable percentage. However, type IV had been found with statistically high percentage in dyskinetic segments, in severe reduction of uptake in both $\mathrm{Tl}$ and mibi images. On the other hand, $\mathrm{Tl}$ segments with normal and mild to moderate uptake showed statistically higher prevalence of type I compared to corresponding MIBI segments. It should be noted that in each segment we chose the most dominant type of mitochondria for assessment. On the other hand, Figure 7 showed the correlation between the mitochondrial types (expressed as mitochondrial score) and rest pre-revascularization wall motion score, myocardial Tl uptake score (late image), GSM1 and GSM2 score. It showed strong statistical correlation which was highest with GSM2 followed by rest echocardiography.

Figure $6 \mathrm{~b}$ revealed the accuracy of assessment of academic viability by LDD, Tl, non TMZ and TMZ GSM, where sensitivity was reduced to be $75 \%, 90 \%, 57.2 \%$ and $89.4 \%$ respectively. Specificity was reduced by

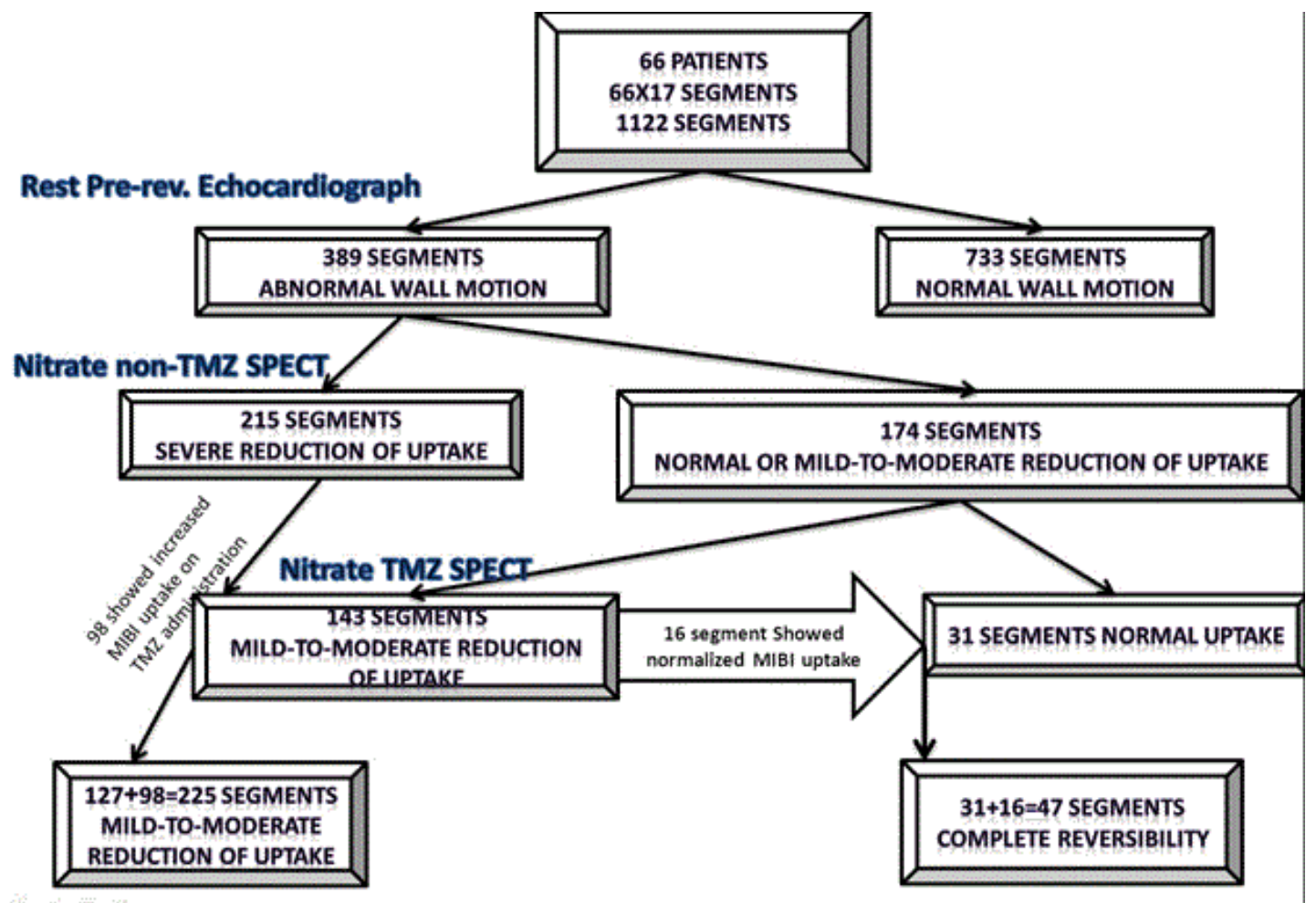

Figure 6: Viability as assessed by nitrate-enhanced 99mTc-MIBI gated SPECT without and with trimetazidine (TMZ). Note that normal uptake segments increased post nitrate and TMZ, in addition to improvement of severely reduced segments. 
Citation: Elsaban K, Alsakhri H, Al-Rashidy A, Wahdan M (2017) Differentiation between Clinical and Academic Myocardial Viability. Complementary Myocardial Perfusion SPECT and Low Dose Dobutamine Echocardiography Role vs. Histopathological Study. J Nucl Med Radiat Ther 8 : 340. doi: $10.4172 / 2155-9619.1000340$

Page 8 of 12

\begin{tabular}{|c|c|c|c|c|c|c|c|c|c|}
\hline & Type I & & Type II & & Type III & & Type IV & & \\
\hline & No. & $\%$ & No. & $\%$ & No. & $\%$ & No. & $\%$ & \\
\hline \multicolumn{10}{|c|}{ Pre-vascularization rest echo } \\
\hline \multicolumn{10}{|l|}{ Normal } \\
\hline Hypokinetic & 733 & 100 & 0 & 0 & 0 & 0 & 0 & 0 & $<0.0001$ \\
\hline Akinetic & 131 & 60.1 & 44 & 20.2 & 39 & 17.9 & 4 & 1.8 & \\
\hline \multirow[t]{2}{*}{ dyskinetic } & 57 & 55 & 12 & 12 & 21 & 20 & 14 & 13 & \\
\hline & 33 & 49.3 & 5 & 7.5 & 11 & 16.4 & 18 & 26.9 & \\
\hline \multicolumn{10}{|l|}{ Thallium R-RD } \\
\hline Normal uptake & 733 & 100 & & 0 & 0 & 0 & 0 & 0 & \\
\hline Mild reduction & 82 & 65.1 & 27 & 21.4 & 15 & 11.9 & 3 & 2.4 & $<0.0001$ \\
\hline Moderate reduction & 65 & 60 & 26 & 24 & 11 & 10 & 6 & 6 & \\
\hline Severe reduction & 44 & 45 & 15 & 15 & 21 & 22 & 17 & 18 & \\
\hline \multicolumn{10}{|l|}{ Non TMZ rest MIBI } \\
\hline Normal uptake & 733 & 100 & 0 & 0 & 0 & 0 & 0 & 0 & \\
\hline Mild reduction & 33 & 50 & 17 & 25.8 & 15 & 22.7 & 1 & 1.5 & $<0.0001$ \\
\hline Moderate reduction & 33 & 42.9 & 18 & 23.4 & 20 & 26 & 6 & 7.8 & \\
\hline Severe reduction & 37 & 17.2 & 17 & 7.9 & 77 & 35.8 & 84 & 39.1 & \\
\hline \multicolumn{10}{|l|}{ TMZ rest MIBI } \\
\hline Normal uptake & 780 & 100 & 0 & 0 & 0 & 0 & 0 & 0 & $<0.0001$ \\
\hline Mild reduction & 51 & 42 & 40 & 33 & 28 & 23 & 2 & 2 & \\
\hline Moderate reduction & 38 & 37 & 41 & 39 & 21 & 20 & 4 & 4 & \\
\hline Severe reduction & 6 & 5.1 & 21 & 17.9 & 44 & 37.6 & 46 & 39.3 & \\
\hline
\end{tabular}

Table 3: Relation between resting and LDD echocardiography and radionuclides uptake and mitochondrial integrity.

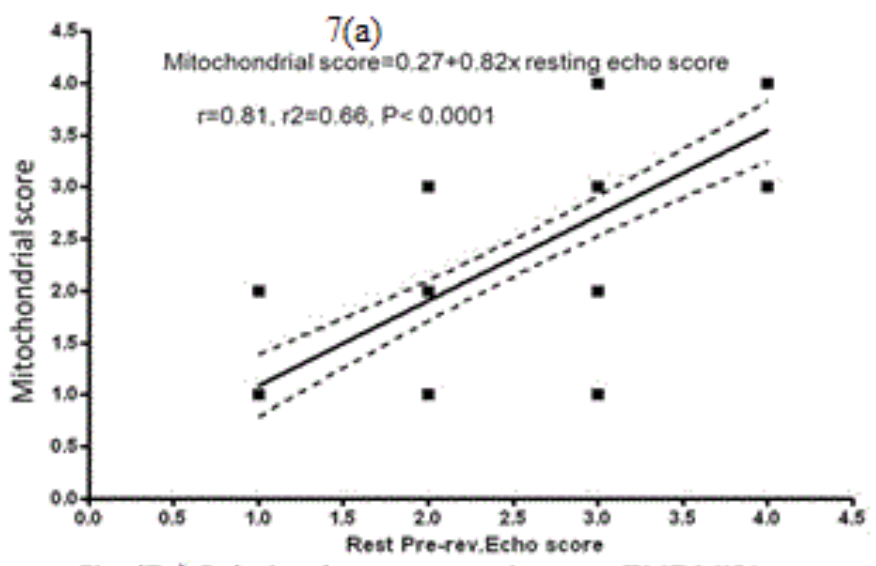

Fig. (7c): Relation between resting non-TMZ MIBI score and mitochondrial score

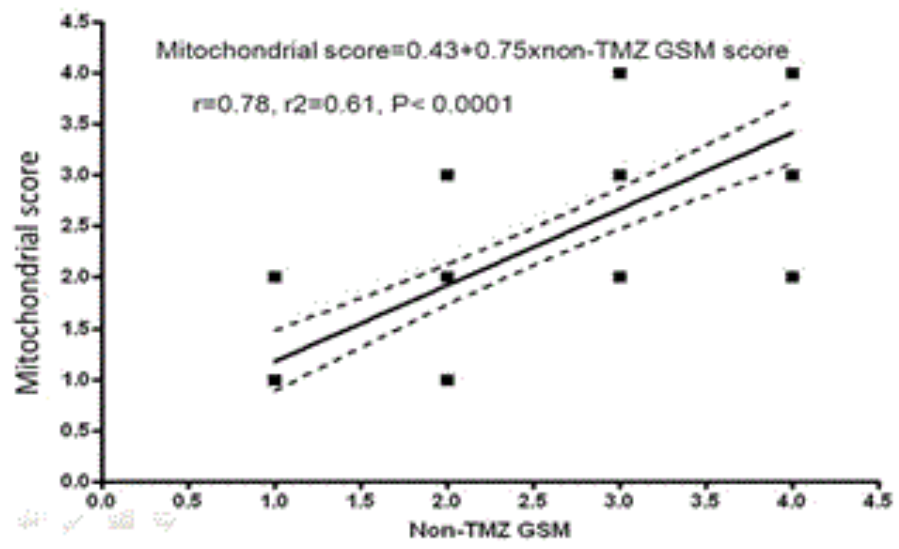

$7(\mathrm{~b})$

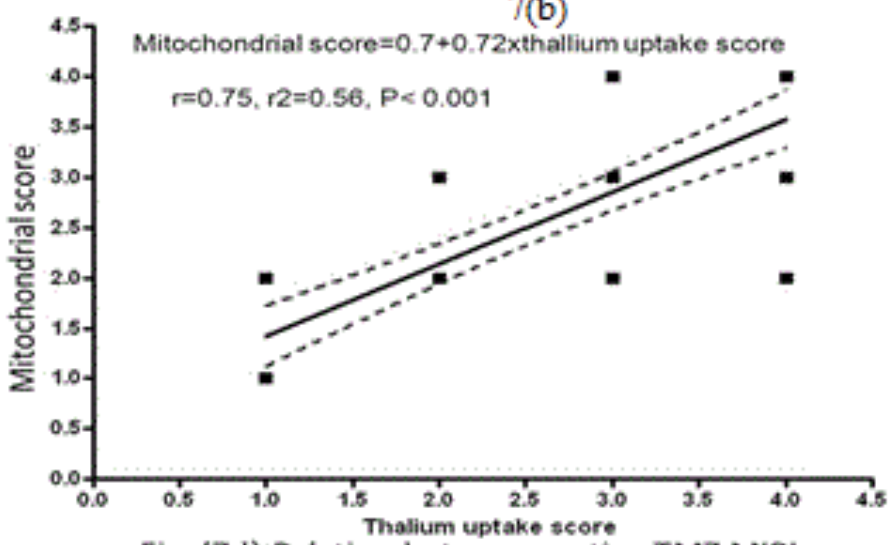

Fig. (7d): Relation between resting TMZ MIBI score and mitochondrial score

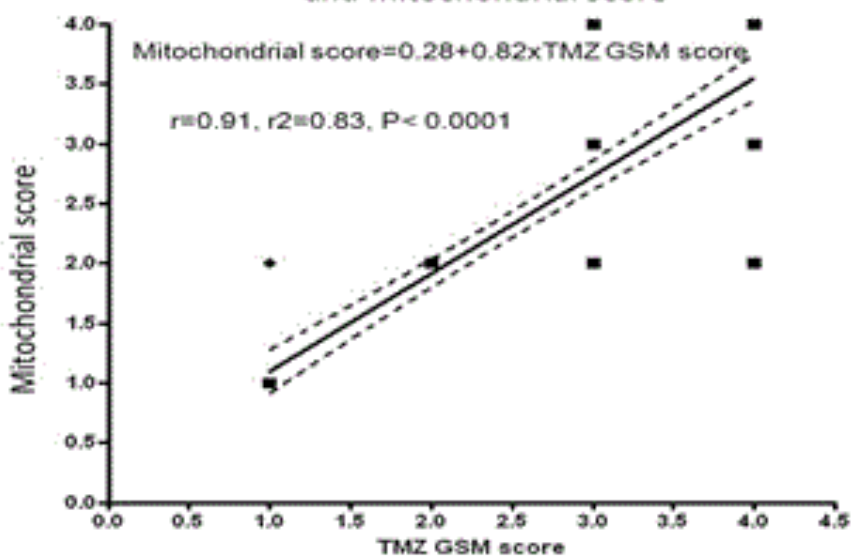

Figure 7: (a) Relation between resting pre-revascularization score and mitochondrial score. (b) Relation between resting thallium score and mitochondrial score. 
Citation: Elsaban K, Alsakhri H, Al-Rashidy A, Wahdan M (2017) Differentiation between Clinical and Academic Myocardial Viability. Complementary Myocardial Perfusion SPECT and Low Dose Dobutamine Echocardiography Role vs. Histopathological Study. J Nucl Med Radiat Ther 8: 340. doi: $10.4172 / 2155-9619.1000340$

Page 9 of 12

LDD to be $88.2 \%$, but increased by $\mathrm{Tl}$ and GSM2 to be $85.6 \%$ and $98 \%$ respectively. The PPV was found to be highest statistically by GSM2 $99.2 \%$ while the NPV was modest $75.8 \%$.

\section{Discussion}

The present study showed that gated SPECT MIBI enhanced by both nitroglycerine and trimetazidine improved the sensitivity and specificity of MIBI SPECT such that it approaches the sensitivity of Tl (highest value) and specificity of LDD echocardiography (highest value) in predicting the viable myocardial segments that will recover function post revascularization. Also, the present study revealed that there was spectrum of changes in the viable myocardium in response to the degree of ischemia in such way that the first to be affected is the mitochondrial level and the last to be affected is the sarcolemma membrane.

\section{Which type of viability we are asking for}

Left ventricular myocardium under ischemic conditions showed variable degrees of pathophysiological changes from reversible (such as stunning and hibernation) to irreversible (such as scar). This spectrum shared one result which is the left ventricular dysfunction and patient handicapping. The target of any management is to separate the reversible from the irreversible changes and assess the magnitude of each. However, there was a controversy for the ideal non-invasive test to do that, from under-estimation (LDD) to overestimation (nuclear imaging) [33]. This could be explained by the fact that some of the viable dysfunctioning myocardium might recover very late (e.g. one year post- revascularization). Accordingly, it could be better to use the available tools as a complementary to each other in such way we can assess the viability spectrum. From this point of view, the current study raised the question which we need to know, clinical viability or academic one.

\section{Thallium and myocardial viability}

Udelson et al. [7] reported positive and negative predictive values of $75 \%$ and $80 \%$, respectively, for predicting functional improvement with the use of rest-redistribution 201Tl SPECT imaging in 18 patients undergoing revascularization. On the other hand, meta-analysis of the positive and negative predictive (PPV and NPV) values reported by McGhie and Weyman [33], showed that the average was $79 \%$ and $82.3 \%$ respectively, similar to the current study which revealed PPV of $90 \%$ and NPV $85.6 \%$. The observed higher PPV in the current study was attributed to the fact that the golden standard in the current study was the postoperative resting echocardiography obtained 6 months later. The degree of match was statistically high $88.9 \%$ between both tests. It must be noted that the first scheme obtained in this study depends on the presence of abnormal wall motion in preoperative resting echocardiography. Accordingly, 289 segments were found to have AWM but with normal (126 segments at the end of thallium imaging) or mild-to-moderate reduction of thallium uptake (198 segments). A possible explanation for this finding is that when infarction involves $<20 \%$ of the wall thickness, hypokinesia is noted; on the other hand, when it involves $>20 \%$ of the wall thickness, akinesis or dyskinesis is seen [34]. According to this fact, the lower specificity reported in the current study $(74.1 \%)$ was attributed to the fact that definition of viability was clinical viability [18].

\section{Techniques used to enhance accuracy of $99 \mathrm{~m}$ Tc-MIBI SPECT}

Use of Gated SPECT imaging: It represents an important advance in the evolution of myocardial functional imaging [35]. Wahba et al.
[36] reported that regional wall motion and thickening can be reliably obtained by gated SPECT and echocardiography. However, wall motion analysis alone may underestimate the presence of viable myocardium because of post-ischaemic stunning [24] and myocardial hibernation. Levine et al. [26] evaluated the benefit of adding functional data to perfusion data from $99 \mathrm{mTc}$-mibi imaging, and found significantly improved sensitivity $(\mathrm{P}<0.025)$ and overall accuracy $(\mathrm{P}<0.05)$. They added that one of the main advantages of gated SPECT is to overcome of partial volume effect in such way a small areas or islands of viable myocardium can be visualized.

Use of Nitrate with 99mTc-MIBI gated SPECT: Like Tl201, the uptake and retention of these agents require intact cell membrane properties. In situations in which rest myocardial blood flow is moderately or severely reduced, however, Tc-99m-labeled agents have inherent disadvantages compared with Tl-201 because of the lack of redistribution [37]. Indeed, the myocardial uptake and retention of Tc-99m-labeled agents (reflecting viable myocardium) appear to be very similar to those of Tl-201 across a relatively wide range of perfusion deficits, except in severe perfusion defects, where they tend to underestimate the degree of viability 7 . Nitroglycerine is known to dilate both diseased and normal coronary arteries [38,39] and to selectively relax the epicardial (conductance) vessels, thereby facilitating flow through collateral channels to zones of myocardial ischemia. In addition, nitrates decrease left ventricular preload and afterload, thereby decreasing the subendocardial compressive forces and improving subendocardial perfusion. This would further facilitate tracer delivery in low-flow states and associated severe left ventricular dysfunction [40].

Accordingly, He et al. [41] reported overall concordance between tetrofosmin SPECT and FDG PET improved from 72\% (94/131) to 82\% $(108 / 131)$ on a segmental basis and from $75 \%(27 / 36)$ to $86 \%(31 / 36)$ on a patient basis. On the other hand, Flotats and Kula [42,43] reported overall agreement between $99 \mathrm{mTc}$-tetrofosmin with nitrates and $201 \mathrm{Tl}$ reinjection regarding the presence of myocardial viability was $90 \%$. This was supported by the RD $201 \mathrm{Tl}$ images. That is why in the current study, nitroglycerine had been used as a basic enhancer for the $99 \mathrm{mTc}$ MIBI uptake in both sets of injections. Yet, the sensitivity of MIBI is till modest in-spite of its high specificity, whereas 215 segments showed severe reduction of uptake i.e. considered non-viable and degree of matching was modest with the postoperative echocardiography $69.4 \%$. This may be attributed to the fact that most of the patients in the current study had multivessel disease with severe stenosis and a prolonged post-ischaemic impairment of coronary vasodilatation ('microvascular stunning) which had been documented [44]. Another explanation which was the base of the current study is that, the severe degree of coronary artery disease in those patients might cause severe degree of degeneration of mitochondria and impairment of its respiratory function [18].

Acute administration of TMZ to the current protocol: This leads to significant reduction of segments with severe reduction of uptake from 215 to 117 segments and increase of number of normal segments from 31 to 47 . This was best presented in the current study by: (1) Highest degree of matching $92.5 \%$ with the postoperative resting echocardiography, (2) Comparable high sensitivity with thallium $93.5 \%$ vs. $94.9 \%$ and high specificity with LDD Echocardiography $90 \%$ vs. 100\%, (3) High PPV 95.9\% and NPV 84.6\%. This was attributed to the fact that the combined use of 2 different markers of viability, such as cellular integrity in a-dyskinetic segments and contractile reserve in hypokinetic segments leading to higher predictive accuracy for 
reversible dysfunction than the assessment of contractile reserve in all asynergic segments with LDD echocardiography. The contractile reserve in the current study was assessed as a first step in our laboratory by reactivation of the degenerated mitochondria (source of energy in the myocardium) using TMZ. TMZ has several actions as a cytoprotective againt myocardial ischemia and necrosis mainly by switching in energy substrate preference with a partial inhibition of fatty acid beta-oxidation together with an increase in glucose oxidation [45] which is recoupled with glycolysis, optimizing the oxygen demand in mitochondria (site of MIBI retention) and preventing the decrease in ATP levels [46]. Thus it protects myocyte structure and function $[46,47]$ not only by limiting the area of necrosis [48] but also by allowing a more rapid return to proper functions once ischaemia is stopped [49]. In addition, It counteracts calcium overload (thus preventing competitive inhibition with mibi) [50], which allows better MIBI uptake by the viable myocardium.

Radionuclide techniques vs. low dose dobutamine echocardiography: The current study showed 109 segments, in the preoperative hypokinetic $(53 / 218,24.3 \%)$ and akinetic $(56 / 104$, i.e. $53.8 \%)$ segments without contractile response to LDD. Of these segments $68 / 109$ (62.4\%) were found to be viable (structurally) [18] by thallium imaging and 50(45.9\%) proved to be viable (functionally) [18] postoperatively by resting echocardiography. The initial consequences to myocardial ischemia are mitochondrial degeneration and calcium influx in the myocardium [51], both affecting mibi uptake. Thus, the observed lowest number of viable segments (174) in the present study concerning first sets of MIBI images (no TMZ) is a normal consequence. In addition, in-spite of its high PPV (96\%) it has the lowest NPV $47.9 \%$ for prediction of post-revascularization functional recovery. The ischemic insult was followed by a mixture of changes resulting in the discordance between thallium (structural assessment) and LDD echocardiography (functional assessment) as mentioned above and can be explained by the followings:

1. Many of these akinetic segments comprise a mixture of scar (often confined to the endocardial layers) and normal myocardium, with adequate perfusion at rest to sustain cellular viability,

2. Severe hypoperfusion confined to the endocardial layers of the myocardium can result in transmural akinesia despite normal midwall and epicardial blood flow [52],

3. $201 \mathrm{Tl}$ uptake in this situation may exceed $50 \%$ of maximal uptake, since fibrosis may extend only from $25 \%$ to $35 \%$ of the transmural thickness of the asynergic myocardial region. Thus, revascularization may not improve resting function in this situation compared with the situation of severe resting regional asynergy without extensive scar (hibernation) [53]. Another potential mechanism that would explain why segments that are viable by $201 \mathrm{Tl}$ criteria do not respond to dobutamine relates to tethering of these segments to regions of extensive scar, which would inhibit recovery of systolic function after successful revascularization. Here, viability is not "overestimated" by $201 \mathrm{Tl}$ scintigraphy [53]. These tethered segments are indeed viable but cannot respond to an inotropic stimulus with enhanced regional thickening or wall motion. Finally, either some stenotic vessels that perfuse viable akinetic regions may not be bypassed at the time of surgery, or revascularization does not result in a significant increase in flow, so that resting wall motion remains depressed [18]. What was shown in the current study revealed that repair of mitochondrial activity will reverse the poor NPV of mibi to be similar to thallium $84.6 \%$ by improving contractility in the presence of enhancement of both blood flow and use of gating SPECT.
Radionuclides $v s$. echocardiographic findings and their relation to ischemic mitochonrdria: Ultrastructural integrity is a key indicator of mitochondrial function and mitochondrial swelling, generally reflected by an increase of the mitochondrial area is a well-accepted hallmark of dysfunction of this organelle [54].

Electron microscopic findings revealed that the severity of degeneration in the cristae of mitochondria in the myocardium is correlated with myocardial washout of 99mTc-MIBI [54]. Therefore an accelerated $99 \mathrm{mTc}$-MIBI clearance from the myocardium is thought to be related to impaired mitochondrial function, including myocardial damage. Similar findings had been observed in the current study where segments with normal mibi uptake showed dominant Type I mitochondria. In contrast to this, the proportions of Type II-IV mitochondria (mitochondria with structural abnormalities) increased considerably in areas with moderate to severe reduction in mibi uptake. According to the percentage of normal mitochondrial structures, the percentage of wall motion improvement in the hypokinetic, akinetic and dyskinetic segments improved in LDD echocardiography [55].

The presence of membrane electrical potential drives the accumulation of $99 \mathrm{mTc}-\mathrm{MIBI}$. A decrease in mitochondrial function in myocardial cell produces a reduction in the mitochondrial inner matrix potential. Trimetazidine had a preferential action on the oxidative system (mainly on complex I), increasing its enzyme activity and decreasing $\mathrm{O}_{2}$ consumption after phosphorylation; this could decrease oxygen free radical production and increase mitochondrial integrity, thus allowing the maintenance of the electrical potential. That is why MIBI uptake had been improved after trimetzidine. An interesting findings in the current study, is the correlation between the mitochondrial integrity and LDD, Tl and MIBI uptake (with and without TMZ). There was a statistically strong correlation between the mitochondrial integrity and the contractile reserve observed in LDD with $\mathrm{r}=0.81(\mathrm{P}<0.0001)$, modest correlation with degree of $\mathrm{Tl}$ and nonTMZ mibi uptake $(\mathrm{r}=0.78$ and $\mathrm{P}<0.0001)$. The most interesting was the elevation of this correlation on adding TMZ where it becomes the strongest, $r=0.91$ and $\mathrm{P}<0.0001$. Another worthy note the observation of PPV and NPV where all the available non invasive tests in the current study were a good positive test for both clinical and academic viability with very high PPV which increased significantly for both Tl abd MIBI GSM2 to detect academic viability. However, the high NPV of both Tl and MIBI GSM2 to detect clinical viability, decreased significantly for academic viability in spite of being still the highest in the current study. From the available data we can grade viability spectrum into 4 type, where grade I viability showed positivity of LDD, Tl, non-TMZ MIBI and TMZ MIBI, grade II showed positivity on in LDD, Tl and TMZ MIBI, with negative non-TMZ MIBI, grade III, positivity is seen only in Tl and TMZ MIBI, while grade IV showed loss of positivity in $\mathrm{Tl}$ and TMZ MIBI.

\section{Conclusion}

The progressive reduction of contractile reserve in stunned, hibernating, and scarred myocardium supports the hypothesis that stunning, hibernation, and scarring are not circumscript pathophysiologic entities but represent gradual ultrastructural damage on the myocyte level. Accordingly, a new concept must be reconsidered which is that retention of technetium-99m mibi is dependent not only on perfusion, but also on the intactness of mitochondria (source of energy and consequently for contractility). Thus, mibi must be considered as a step of metabolic assessment of viability. In addition, as a main focus for viability study, the prediction of improvement of 
Citation: Elsaban K, Alsakhri H, Al-Rashidy A, Wahdan M (2017) Differentiation between Clinical and Academic Myocardial Viability. Complementary Myocardial Perfusion SPECT and Low Dose Dobutamine Echocardiography Role vs. Histopathological Study. J Nucl Med Radiat Ther 8 : 340. doi: $10.4172 / 2155-9619.1000340$

either the global or regional contractile function after revascularization, the sensitivity and specificity of enhanced technetium-99m mibi gated SPECT enhanced by nitroglycerine and trimetazidine, proves in this study its validity for this target. From the available non-invasive tests we can grade viability spectrum into 4 grades.

\section{References}

1. Acampa W, Petretta M, Florimonte L, di Santolo MS, Cuocolo A (2001) Mibi SPECT in the detection of myocardial viability in patients with chronic ischemic left ventricular dysfunction: Comparison between visual and quantitative analysis. J Nucl Card 7: 406-413.

2. Dilsizian V, Rocco TP, Freedman NM, Leon MB, Bonow RO (1990) Enhanced detection of ischemic but viable myocardium by the reinjection of thallium after stress-redistribution imaging. N Engl J Med 323: 141-146.

3. Ohtani H, Tamaki N, Yonekura Y, Mohiuddin IH, Hirata K, et al. (1990) Value of thallium-201 reinjection after delayed SPECT imaging for predicting reversible ischemia after coronary artery bypass grafting. Am J Cardiol 66: 394-399.

4. Marzullo P, Parodi O, Reisenhofer B, Sambuceti G, Picano E, et al. (1993) Value of rest thallium-201/technetium-99m mibi scans and dobutamine echocardiography for detecting myocardial viability. Am J Cardiol 71: 166-172.

5. Cuocolo A, Pace L, Ricciardelli B, Chiariello M, Trimarco B, et al. (1992) Identification of viable myocardium in patients with chronic artery disease: Comparison of thallium-201 scintigraphy with reinjection and technetium-99m methoxyisobutyl isonitril. J Nucl Med 33: 505-511.

6. Dilsizian V, Arrighi JA, Diodati JG, Quyyumi AA, Alavi K, et al. (1940) Myocardial viability in patients with chronic coronary artery disease: comparison of Tc-99m mibi with thallium 201 reinjection and [18F]fluorodeoxyglucose. Circulation 89 : 578-587.

7. Udelson JE, Coleman PS, Metherall J, Pandian NG, Gomez AR, et al. (1994) Predicting recovery of severe regional ventricular dysfunction: Comparison of resting scintigraphy with 201TI and 99mTc-mibi. Circulation 89: 2552-2561.

8. Piwnica-Worms D, Kronague JF, Chiu ML (1990) Uptake and retention of hexakis (2-methoxy isobutyl isonitrile) technetium (I) in cultured chick myocardial cells: mitochondrial and plasma membrane potential. Circulation. 82: $1826-1838$

9. Bisi G, Sciagrà R, Santoro GM, Rossi V, Fazzini PF (1995) Technetium-99m mibi imaging with nitrate infusion to detect viable hibernating myocardium and predict post revascularization recovery. J Nucl Med 36: 1994-2000.

10. Senior R, Kaul S, Raval U, Lahiri A (2002) Impact of revascularization and myocardial viability determined by nitrate-enhanced Tc-99m mibi and TI-201 imaging on mortality and functional outcome in ischemic cardiomyopathy. $J$ Nucl Cardiol 9: 454-462.

11. He ZX, Medrano R, Hays JT (1997) Nitrogylcerine augmented TI-201 reinjection enhances detection of reversible myocardial hypoperfusion: A randomized, double-blind, parallel, placebo-controlled trial. Circulation 95: 1799-1805.

12. Basu S, Senior R, Raval U, Lahiri A (1997) Superiority of nitrate-enhanced 201TI over conventional redistribution 201TI imaging for prognostic evaluation after myocardial infarction and thrombolysis. Circulation 96: 2932-2937.

13. Bax JJ, Wijns W, Cornel JH, Visser FC, Boersma E, et al. (1997) Accuracy of currently available techniques for prediction of functional recovery after revascularization in patients with left ventricular dysfunction due to chronic coronary artery disease: comparison of pooled data. J Am Coll Cardiol 30 : 1451-1460.

14. Senior R, Lahiri A (1995) Enhanced detection of myocardial ischemia by stress dobutamine echocardiography utilizing the "biphasic" response of wall thickening during low and high dose dobutamine infusion. J Am Coll Cardiol 26: $26-32$.

15. Afridi I, Kleiman NS, Raizner AE, Zoghbi WA (1995) Dobutamine echocardiography in myocardial hibernation. Optimal dose and accuracy in predicting recovery of ventricular function after coronary angioplasty. Circulation 91: 663-670.

16. Panza JA, Dilsizian V, Laurienzo JM, Curiel RV, Katsiyiannis PT (1995) Relation between thallium uptake and contractile response to dobutamine. Implication regarding myocardial viability in patients with chronic coronary artery disease and left ventricular dysfunction. Circulation 91: 990-998.

17. Cornel JH, Bax JJ, Elhendy A, Visser FC, Boersma E, et al. (1999) Agreement and disagreement between "metabolic viability" and "contractile reserve" in akinetic myocardium. J Nucl Cardiol 6: 383-388.

18. Bax JJ, Poldermans D, Elhendy A, Boersma E, Rahimtoola SH (2001) Sensitivity, specificity and predictive accuracies of various non-invasive techniques for detecting hibernating myocardium. Curr Probl Cardiol 26: 147186

19. Nagueh SF, Mikati I, Weilbaecher D, Reardon MJ, Al-Zaghrini GJ, et al. (1999) Relation of the contractile reserve of hibernating myocardium to myocardial structure in humans. Circulation 100: 490-496.

20. Pagano D, Townend JN, Parums DV, Bonser RS, Camici PG (2000) Hibernating myocardium: Morphological correlates of inotropic stimulation and glucose uptake. Heart 83: 456-461.

21. Schinkel AF, Bax JJ, van Domburg R, Elhendy A, Valkema R, et al. (2003) Dobutamine-induced contractile reserve in stunned, hibernating, and scarred myocardium in patients with ischemic cardiomyopathy. J Nucl Med 44: 127-133.

22. Demaison L, Fantini E, Sentex E, Grynberg A (1995) Trimetazidine: In vitro influence on heart mitochondrial function. Am J Cardiol 76: 31B-37B.

23. El-Kady T, El-Sabban Kh (2003) Dobutamine stress echocardiography versus thallium SPECT (stress-redistribution-reinjection protocol) in detecting patients with hibernating myocardium. N Egypt J Med 28: 31-39.

24. El-Sabban Kh, El-Gabaly M (2003) Role of gated SPECT in detection of poststress LV stunning and its significance. N Egypt J Med 28: 40-52.

25. Cerqueira MD, Weissman NJ, Dilsizian V, Jacobs AK, Kaul S, et al. (2002) Standardized myocardial segmentation and nomenclature for tomographic imaging of the heart. A statement for healthcare professionals from the cardiac imaging committee of the council on clinical cardiology of the American Heart Association . Circulation 105: 539-542.

26. Levine MG, McGill CC, Ahlberg AW (1999) Functional assessment with electrocardiographic gated single-photon emission computed tomography improves the ability of technetium-99m sestamibi myocardial perfusion imaging to predict myocardial viability in patients undergoing revascularization. Am J Cardiol 83: 1-5.

27. Maruyama A, Hasegawa S, Paul AK (2002) Myocardial viability assessment with gated SPECT Tc-99m tetrofosmin \% wall thickening: comparison with $\mathrm{F}-18$ FDG-PET. Ann Nucl Med 16: 25-32.

28. Schiller NB, Shah PM, Crawford M, DeMaria A, Devereux R, et al. (1989) Recommendations for quantitation of the left ventricle by two-dimensional echocardiography. American society of echocardiography committee on standards, subcommittee on quantitation of two-dimensional echocardiograms. J Am Soc Echocardiogr 2: 358-567.

29. Austen WG, Edwards JE, Frye RL, Gensini GG, Gott VL, et al. (1975) A reporting system on patients evaluated for coronary artery disease: Report of the ad hoc committee for grading of coronary artery disease, council on cardiovascular surgery, american heart association. Circulation 51: 5-40.

30. Cooper LT, Baughman KL, Feldman AM, Frustaci A, Jessup M, et al. (2007) The role of endomyocardial biopsy in the management of cardiovascular disease: $A$ scientific statement from the American Heart Association, the american college of cardiology and the european society of cardiology. Endorsed by the heart failure society of america and the heart failure association of the european society of cardiology. J Am Coll Cardiol 50: 1914-1931.

31. Saraste A, Ukkonen H, Kajander S, Knuuti J (2010) Integrated anatomy and viability assessment PET-CT. Eurolntervention. 6 Suppl G: G132-G137.

32. Mendenhal E, Smith MA, Gross BH (1986) Medical statistics

33. McGhie Al, Weyman (1996) A searching for hibernating myocardium. Time to reevaluate investigative strategies? Circulation 94: 2685-2688.

34. Kaul S (1996) Response of dysfunctional myocardium to dobutamine. The eyes see what the mind knows. J Am Coll Cardiol 27: 1608-1611.

35. Bonow RO (1997) Gated myocardial perfusion imaging for measuring left ventricular function. J Am Coll Cardiol 30: 1649-1650.

36. Wahba $\mathrm{FH}$, Bavelaar-Croon $\mathrm{C}$ DL, Baur L HB, Zwinderman AH, Van Roosmalen R PM, et al. (2001) Detection of residual wall motion after sustained myocardial infarction by gated $99 \mathrm{Tcm}$-tetrofosmin SPECT: A comparison with echocardiography. N Med Commu 22: 175-182.

37. Bonow RO, Dilsizian V (1992) Thallium-201 and technetium-99m-mibi fo assessing viable myocardium. J Nucl Med 33: 815-818. 
Citation: Elsaban K, Alsakhri H, Al-Rashidy A, Wahdan M (2017) Differentiation between Clinical and Academic Myocardial Viability. Complementary Myocardial Perfusion SPECT and Low Dose Dobutamine Echocardiography Role vs. Histopathological Study. J Nucl Med Radiat Ther 8: 340. doi: $10.4172 / 2155-9619.1000340$

38. Fam WM and McGregor M (1968) Effect of nitroglycerin and dipyridamole on regional coronary resistance. Circ Res 22: 649-659.

39. Brown BG, Bolson E, Petersen RB, Pierce CD, Dodge HT (1981) The mechanisms of nitroglycerin action: Stenosis vasodilation as a major component of the drug response. Circulation 64: 1089-1097.

40. Di Carli MF (2003) The quest for myocardial viability: Is there a role for nitrateenhanced imaging? J Nucl Card 10: 696-699.

41. He W, Acampa W, Mainolfi C, Menna F, Sorrentino AR et al. (2003) Tc-99m tetrofosmin tomography after nitrate administration in patients with ischemic left ventricular dysfunction: Relation to metabolic imaging by PET. J Nucl Cardiol 10: $599-606$

42. Flotats A, Carrió I, Estorch M, Bernà L, Catafau AM et al. (1997) Nitrate administration to enhance the detection of myocardial viability by technetium99m tetrofosmin single-photon emission tomography. Eur J Nucl Med 24: 767773.

43. Kula M, Tutus A, Ünal S, Topsakal R, Ergin A (2003) Technetium-99mtetrofosmin imaging with incremental nitroglycerin infusion to detect severely ischaemic but viable myocardium: A comparative study with thallium-201. Nucl Med Commun 24: 987-994

44. Bolli R (1992) Myocardial stunning in man. Circulation 86: 1671-1691.

45. Kantor PF, Lucien A, Kozak R, Lopaschuk GD (2000) The antianginal drug trimetazidine shifts cardiac energy metabolism from fatty acid oxidation to glucose oxidation by inhibiting mitochondrial long- chain 3-ketoacyl coenzyme A thiolase. Circ Res 86: 580-588.

46. Fantini E, Demaison L, Sentex E, Grynberg A, Athias P (1994) Some biochemical aspects of the protective effect of trimetazidine on rat cardiomyocytes during hypoxia and re-oxygenation. J Mol Cell Cardiol 26 :949-958.

47. Lavanchy N, Martin J, Rossi A (1987) Anti-ischemic effects of trimetazidine:
31 P-NMR spectroscopy in the isolated rat heart. Arch Int Pharmacodyn Ther 286: $97-110$

48. Ruiz-Meana M, Garcia-Dorado D, Juliá M, González MA, Inserte J et al. (1996) Pre-treatment with trimetazidine increases sarcolemmal mechanical resistance in reoxygenated myocytes. Cardiovasc Res 32: 587-592.

49. Fantini E, Athias P, Demaison L, Grynberg A (1997) Protective effects of trimetazidine on hypoxic cardiac myocytes from the rat. Fundam Clin Pharmacol 11: $427-439$

50. El Banani H, Bernard M, Baetz D, Cabanes E, Cozzone P et al. (2000) Changes in intracellular sodium and $\mathrm{pH}$ during ischemia- reperfusion are attenuated by trimetazidine. Comparison between low and zero-flow ischemia. Cardiovasc Res 47: 688-696.

51. Edwards NC, Sinusas AJ, Bergin JD, Watson DD, Ruiz M et al. (1992) Influence of subendocardial ischemia on transmural myocardial function. Am J Physiol 262: H568-H576.

52. Beller GA (1996) Comparison of 201TI Scintigraphy and Low-Dose Dobutamine Echocardiography for the Noninvasive Assessment of Myocardial Viability. Circulation 94: 2681-2684.

53. Hayashi D, Ohshima S, Isobe S, Cheng XW, Unno K et al. (2013) Increased $99 \mathrm{~m}$ Tc-mibi washout reflects impaired myocardial contractile and relaxation reserve during dobutamine stress due to mitochondrial dysfunction in dilated cardiomyopathy patients. J Am Coll Cardiol 61: 2007-2017.

54. Matsuo S, Nakajima K, Kinuya S (2013) Evaluation of Cardiac Mitochondria Function by a Nuclear Imaging Technique using Technetium-99m-MIBI Uptake Kinetics. Asia Oceania J Nucl Med Biol 1: 39-43.

55. Monteiro P, Duarte AI, Gonçalves LM, Moreno A, Providência LA (2004) Protective effect of trimetazidine on myocardial mitochondrial function in an ex-vivo model of global myocardial ischemia. Eur J Pharmacol 25: 123-128. 